\title{
Alexithymia in patients with type 2 diabetes mellitus: the role of anxiety, depression, and glycemic control
}

This article was published in the following Dove Press journal:

Patient Preference and Adherence

20 July 2016

Number of times this article has been viewed

\author{
Dilek Avci' \\ Meral Kelleci ${ }^{2}$ \\ 'Department of Nursing, Faculty \\ of Health Sciences, Bandirma \\ Onyedi Eylul University, Balikesir, \\ ${ }^{2}$ Department of Nursing, Faculty \\ of Health Sciences, Cumhuriyet \\ University, Sivas, Turkey
}

Objective: This study was aimed at determining the prevalence of alexithymia in patients with type $2 \mathrm{DM}$ and the factors affecting it.

Methods: This cross-sectional study was conducted with 326 patients with type 2 DM. Study data were collected with the Personal Information Form, Toronto Alexithymia Scale, and Hospital Anxiety and Depression Scale. Glycemic control was assessed by glycated haemoglobin (HbA1c) results. The analysis was performed using descriptive statistics, chi-square test, Pearson's correlation, and logistic regression analysis.

Results: Of the patients, $37.7 \%$ were determined to have alexithymia. A significant relationship was determined between alexithymia and $\mathrm{HbAlc}$, depression, and anxiety. According to binary logistic regression analyses, alexithymia was 2.63 times higher among those who were in a paid employment than those who were not, 2.09 times higher among those whose HbA1c levels were $\geq 7.0 \%$ than those whose HbA1c levels were $<7.0 \%, 3.77$ times higher among those whose anxiety subscale scores were $\geq 11$ than those whose anxiety subscale scores were $\leq 10$, and 2.57 times higher among those whose depression subscale scores were $\geq 8$ than those whose depression subscale scores were $\leq 7$.

Conclusion: In this study, it was determined that two out of every five patients with DM had alexithymia. Therefore, their treatment should be arranged to include mental health care services.

Keywords: diabetes mellitus, alexithymia, mental symptoms, HbAlc

\section{Introduction}

Type 2 diabetes mellitus (DM) is one of the most common chronic diseases all over the world and is a major health problem due to its growing prevalence. ${ }^{1-5}$ Like all other chronic diseases, DM can lead to physical, mental, and social problems. ${ }^{6,7}$ As blood glucose levels affect brain and mental functions, mental disorders particularly depression and anxiety disorders are more prevalent in patients with DM than in the general population. ${ }^{8-13}$ Several studies on the issue have demonstrated that $\sim 30 \%$ of the patients with DM exhibit depression symptoms and $20 \%$ exhibit anxiety symptoms and that DM increases the risk of mental disorders. ${ }^{9,14,15}$

In patients with DM, poor metabolic control is reported to be associated not only with psychiatric disorders but also with alexithymia. ${ }^{16,17}$ Alexithymia is defined as the inability to distinguish between emotions, thoughts, and physiological responses and difficulty in recognizing and describing emotions. ${ }^{18,19}$ Initially, alexithymia was proposed to describe the symptoms observed in psychosomatic patients; however, today it is recognized as a personality trait affecting various physical and psychiatric
Department of Nursing, Faculty of Health Sciences, Bandirma Onyedi Eylul University, Kurtulus Street, 10200

Bandirma/Balikesir, Turkey

Tel +902667l8 6400

Fax +90 2667186414

Email daydinenator@gmail.com 
disorders. ${ }^{20-23}$ It is also reported that DM is associated with alexithymia, that individuals with alexithymia experience problems in identifying and regulating bodily signals and sensations, that they tend to perceive stress at a higher level, and that this condition is associated with a poor metabolic control. ${ }^{16,24-27}$ Alexithymia is also reported to be associated with depression and anxiety in patients with DM. ${ }^{17,27,28}$

Alexithymic features and psychiatric symptoms negatively affect the clinical presentation, severity and progression of the disease, and compliance with the treatment. ${ }^{24,27,29}$ The inability of persons with DM to suppress or describe their emotions increases physical and mental symptoms, promotes alexithymic features, and affects their ability to manage the disease. ${ }^{28}$ Therefore, during the assessment of patients, it is important to analyze alexithymic features and related factors for the planning of treatment and health care. On the other hand, there is a gap in the literature related to studies investigating alexithymia, anxiety, and depression symptoms in patients with type $2 \mathrm{DM}$. Based on this rationale, the present study was aimed at determining the prevalence of alexithymia and affecting factors. The results of the study are expected to contribute to control DM through holistic evaluation of patients with DM.

\section{Methods}

\section{Study design}

This cross-sectional study was conducted between June 2015 and November 2015 in Bandirma State Hospital, Turkey.

\section{Study population}

The minimum sample size was calculated with the PASS 11 software. The sample size was calculated according to the frequency of an event when the population size is unknown. No nationwide and regional study has been conducted to determine the prevalence of alexithymia in patients with type 2 DM in Turkey. Therefore, the prevalence value was accepted as $50.0 \%$ to calculate the minimum sample size. The minimum sample size was calculated as $n=300$ by using $P=0.5-0.6$ and $\beta=0.93$ (power) for the prevalence of alexithymia. In order to achieve the minimum sample size, of the 627 patients who were diagnosed with type 2 DM according to the International Classification of Diseases System (ICD-10), were hospitalized between June 2015 and November 2015, and met the inclusion criteria, 326 were included in the study. The inclusion criteria were as follows: agreeing to participate in the study, being older than 18 years, and having been diagnosed with type $2 \mathrm{DM}$ (at least 6 months ago). The exclusion criterion was having perception disorders. Thirty-two patients who refused to participate in the study were excluded from the study.

\section{Measures}

Data were collected using the Personal Information Form, Toronto Alexithymia Scale (TAS), Hospital Anxiety and Depression Scale, and HbA1c test results.

\section{Personal Information Form}

The form prepared by the researchers through a literature review includes 13 items questioning sociodemographic and disease characteristics of the patients.

\section{TAS-20}

The scale developed by Bagby et $\mathrm{al}^{30}$ is used to assess alexithymia defined as a person's inability to identify and describe his/her emotions. The scale is a 5-point Likert-type, self-rating scale and consists of 20 items. The items are rated from 1 to 5 . The TAS has three subscales: Difficulty Identifying Feelings subscale (TAS-1), Difficulty Describing Feelings subscale (TAS-2), and Externally Oriented Thinking subscale (TAS-3). The Turkish validity and reliability study of the scale was performed twice, once by Sayar et al, ${ }^{31}$ and once by Gulec et al. ${ }^{32}$ Scores are calculated for each subscale, and the sum of the subscale scores is used as the total score of the overall scale. The total score to be obtained from the scale ranges between 20 and 100. The Cronbach alpha for the total TAS-20 scale was $0.78 .^{32}$ In the reliability and validity study of the scale, the cutoff point was determined as 61 , and individuals whose score was $>61$ were considered as alexithymic. ${ }^{31}$ The Cronbach alpha reliability coefficient of the scale was calculated as 0.91 in the present study.

\section{HADS}

The scale developed by Zigmond and Snaith is a self-rating scale used to determine the risk of depression and anxiety in people with a physical illness. ${ }^{33}$ The Turkish validity and reliability study of the scale was carried out by Aydemir et al. ${ }^{34}$ The scale has two subscales: anxiety (HAD-A) and depression (HAD-D). The Cronbach alpha for anxiety was 0.85 and that for depression was $0.77 .{ }^{34}$ The 4-point Likert-type scale consists of 14 items in which the seven odd-numbered items measure anxiety and the seven even-numbered items measure depression. Possible scores to be obtained from each subscale range from 0 to 21 . In the reliability and validity study of the scale, while the cutoff point for the anxiety subscale was calculated as 11 , it was calculated as 8 for the depression subscale. Those whose scores are above these 
points are in the at-risk group. ${ }^{34}$ Cronbach alpha reliability coefficient of the scale was calculated as 0.90 for anxiety and 0.84 for depression in this present study.

\section{$\mathrm{HbAlc}$}

In this study, for the assessment of glycemic control, the results obtained with the $\mathrm{HbA} 1 \mathrm{c}$ test proposed by the American Diabetes Association were used because this test reflects the average plasma glucose level in the previous $8-12$ weeks, and it can be done at any time of the day without requiring special preparation such as fasting. ${ }^{35}$ For the analysis of the HbA1c test results, the American Diabetes Association's diagnostic criteria for DM (2015) were considered. According to the criteria, the $\mathrm{HbA} 1 \mathrm{c}$ level $<7.0 \%$ shows that glycemic control was achieved. ${ }^{1} \mathrm{HbAlc}$ levels obtained from the results of the biochemical tests performed in the public hospital laboratory on the first day of hospitalization of the patients were recorded in the questionnaire.

\section{Data collection}

The Personal Information Form, TAS, and HADS were administered on the patients who agreed to participate in the study and gave their written consent. It took $\sim 30$ minutes to fill in the data collection tools.

\section{Ethical considerations}

Legal permission was obtained from the Balikesir Public Hospitals Union General Secretariat, and the ethical approval was obtained from Balikesir University Clinical Research Ethics Committee (decision date and no 2015/35). Participation in the study was voluntary. After the participants were informed about the purpose of the study, their written informed consent was obtained.

\section{Statistical analysis}

Study data were analyzed using the Statistical Package for Social Sciences 18.0 (SPSS Inc., Chicago, IL, USA). To analyze the data, descriptive statistics, chi-square test, Pearson's correlation, and backward likelihood ratio model for binary logistic regression analysis were used. For the binary logistic regression analyses, according to the scores obtained from TAS, the patients were divided into two groups: patients with a TAS score $\geq 61$ were considered as alexithymic and patients with a TAS score $\leq 60$ were considered as nonalexithymic. ${ }^{31}$ In the binary logistic regression analyses, the TAS score was considered as dependent variable, and age, sex, education level, employment status, perceived income level, duration of disease, presence of a comorbid chronic disease, treatment type, presence of complications, $\mathrm{HbAlc}$ level, and risk of anxiety and depression were considered as continuous/ordinal independent variables, all of which were demonstrated to be significantly associated with alexithymia through the univariate analysis and studies in the literature. Anxiety, depression, and $\mathrm{HbA1c}$ variables correlated with the Pearson's correlation analysis. However, the correlation coefficient was calculated to be $<0.70$. Therefore, anxiety, depression, and $\mathrm{HbA} 1 \mathrm{c}$ variables were also included in the model. Before the binary logistic regression analyses, test of significance (omnibus test, $P<0.05$ ) and goodness-offit test (Hosmer-Lemeshow test, $P>0.05$ ) were applied for the model used.

\section{Results}

Of the participants, $62.0 \%$ were in the $\geq 65$ years age group, $52.5 \%$ were female, $64.5 \%$ were primary school and lower graduates, $63.8 \%$ were married, $94.5 \%$ were unemployed, $88.3 \%$ perceived their income as moderate, $23.3 \%$ were diagnosed $\geq 11$ years ago, $64.1 \%$ had comorbid chronic disease, $59.5 \%$ had been prescribed insulin + diet as medication, $26.1 \%$ had complications, and the $\mathrm{HbA} 1 \mathrm{c}$ level was $\geq 7.0 \%$ in $63.5 \%$.

The mean \pm standard deviation scores of the participants obtained from the TAS- 1 , TAS-2, TAS-3, and TAS-20 were $17.41 \pm 5.93,14.85 \pm 3.51,24.65 \pm 4.71$, and $56.92 \pm 9.05$ respectively, and $37.7 \%$ of the patients were determined to be alexithymic (Table 1).

The mean scores of the participants obtained from the anxiety and depression subscales were as follows: $32.5 \%$ of the participants obtained a mean score of $\geq 11$ from the anxiety subscale and $45.1 \%$ of them obtained a mean score of $\geq 8$ from the depression subscale (Table 2).

The alexithymia status of the participants in terms of some of their characteristics is given in Table 3. Alexithymia was more severe in participants who were female, who worked in

Table I Mean scores for the Toronto Alexithymia Scale and the prevalence of alexithymia

\begin{tabular}{llll}
\hline Variables & $\mathbf{X} \pm \mathbf{S D}$ & $\mathbf{M i n}-\mathbf{m a x}$ & $\mathbf{n}(\%)$ \\
\hline TAS-I & $17.4 \mathrm{I} \pm 5.93$ & $6-29$ & \\
TAS-2 & $14.85 \pm 3.5 \mathrm{I}$ & $8-24$ & \\
TAS-3 & $24.65 \pm 4.7 \mathrm{I}$ & $9-35$ & \\
TAS-20 & $56.92 \pm 9.05$ & $33-85$ & \\
$\leq 60$ nonalexithymic & & & $203(62.3)$ \\
$\geq 6 \mathrm{I}$ alexithymic & & & $123(37.7)$ \\
\hline
\end{tabular}

Notes: TAS-I, Difficulty Identifying Feelings; TAS-2, Difficulty Describing Feelings; TAS-3, Externally Oriented Thinking; TAS-20, Toronto Alexithymia Scale.

Abbreviations: max, maximum; min, minimum; SD, standard deviation; $X$, mean. 
Table 2 Mean scores for the anxiety and depression subscales

\begin{tabular}{llll}
\hline Variables & $\mathbf{n}(\%)$ & $\mathbf{X} \pm$ SD & Min-max \\
\hline Anxiety & & & \\
$\leq 10$ points & $220(67.5)$ & $8.91 \pm 2.88$ & $3-18$ \\
$\geq 11$ points & $106(32.5)$ & & \\
Depression & & & \\
$\leq 7$ points & $179(54.9)$ & $9.36 \pm 3.92$ & 21 \\
$\geq 8$ points & $147(45.1)$ & & \\
\hline
\end{tabular}

Abbreviations: max, maximum; min, minimum; SD, standard deviation; $X$, mean. a paid job, whose duration of disease was $\geq 11$ years, whose HbAlc level was $\geq 7.0 \%$, whose anxiety subscale score was $\geq 11$, and whose depression subscale score was $\geq 8$ than their counterparts $(P<0.05)$.

The correlation between alexithymia, mean $\mathrm{HbA} 1 \mathrm{c}$ of the participants, and the anxiety and depression scores is given in Table 4. Although there was a strong positive significant correlation between alexithymia and $\mathrm{HbA} 1 \mathrm{c}$ and depression,

Table 3 Alexithymia status of the participants in terms of some of their characteristics

\begin{tabular}{|c|c|c|c|c|c|c|}
\hline \multirow[t]{2}{*}{ Variables $(n=326)$} & \multicolumn{2}{|c|}{$\begin{array}{l}\text { Nonalexithymic } \\
\text { TAS-20 }(\leq 60)\end{array}$} & \multicolumn{2}{|c|}{$\begin{array}{l}\text { Alexithymic } \\
\text { TAS-20 }(\geq 6 \mathrm{I})\end{array}$} & \multirow[t]{2}{*}{$\chi^{2}$} & \multirow[t]{2}{*}{$P$-value } \\
\hline & $\mathbf{n}$ & $\%$ & $n$ & $\%$ & & \\
\hline Age (years) & & & & & 0.984 & 0.321 \\
\hline $45-64$ & 73 & 58.9 & 51 & 41.1 & & \\
\hline$\geq 65$ & 130 & 64.4 & 72 & 35.6 & & \\
\hline Sex & & & & & 9.515 & 0.002 \\
\hline Female & 93 & 54.4 & 78 & 45.6 & & \\
\hline Male & 110 & 71.0 & 45 & 29.0 & & \\
\hline Education level & & & & & 0.033 & 0.855 \\
\hline Primary school and lower & 130 & 61.9 & 80 & 38.1 & & \\
\hline Secondary and high school & 73 & 62.9 & 43 & 37.1 & & \\
\hline Marital status & & & & & 3.198 & 0.074 \\
\hline Married & 122 & 58.7 & 86 & 41.3 & & \\
\hline Single/widow & 81 & 68.6 & 37 & 31.4 & & \\
\hline Employment status & & & & & 13.006 & $<0.00$ I \\
\hline Working & 4 & 22.2 & 14 & 77.8 & & \\
\hline Does not work & 199 & 64.6 & 109 & 35.4 & & \\
\hline Perceived income level & & & & & 4.594 & 0.101 \\
\hline Good & 10 & 62.5 & 6 & 37.5 & & \\
\hline Moderate & 184 & 63.9 & 104 & 36.1 & & \\
\hline Bad & 9 & 40.9 & 13 & 59.1 & & \\
\hline Duration of illness (years) & & & & & 9.924 & 0.019 \\
\hline$<1$ & 53 & 66.3 & 27 & 33.8 & & \\
\hline $\mathrm{I}-5$ & 64 & 73.6 & 23 & 26.4 & & \\
\hline $6-10$ & 46 & 55.4 & 37 & 44.6 & & \\
\hline$\geq \mathrm{II}$ & 40 & 52.6 & 36 & 47.4 & & \\
\hline Presence of a comorbid chronic disease & & & & & 0.561 & 0.454 \\
\hline Yes & 127 & 60.8 & 82 & 39.2 & & \\
\hline No & 76 & 65.0 & 40 & 35.0 & & \\
\hline Type of treatment & & & & & 2.508 & 0.113 \\
\hline Insulin + diet & 114 & 58.8 & 80 & 41.2 & & \\
\hline Oral antidiabetic + diet & 89 & 67.4 & 43 & 32.6 & & \\
\hline Presence of complications & & & & & 3.252 & $0.07 \mid$ \\
\hline Yes & 46 & 54.1 & 39 & 45.9 & & \\
\hline No & 157 & 65.1 & 84 & 34.9 & & \\
\hline HbA Ic level (\%) & & & & & 9.372 & 0.002 \\
\hline$<7.0$ & 87 & 73.1 & 32 & 26.9 & & \\
\hline$\geq 7.0$ & 116 & 56.0 & 91 & 44.0 & & \\
\hline Anxiety & & & & & 37.206 & $<0.00$ I \\
\hline$\leq 10$ points & 162 & 73.6 & 58 & 26.4 & & \\
\hline$\geq I 1$ points & 41 & 38.7 & 65 & 61.3 & & \\
\hline Depression & & & & & 22.241 & $<0.00 \mathrm{I}$ \\
\hline$\leq 7$ points & 132 & 73.7 & 47 & 26.3 & & \\
\hline$\geq 8$ points & 7I & 48.3 & 76 & 51.7 & & \\
\hline
\end{tabular}

Abbreviation: TAS-20, Toronto Alexithymia Scale. 
Table 4 Correlation between alexithymia and $\mathrm{HbAlc}$, anxiety, and depression

\begin{tabular}{llll}
\hline Variables & $\mathbf{I}$ & $\mathbf{2}$ & $\mathbf{3}$ \\
\hline I. Alexithymia & $\mathrm{I}$ & - & - \\
2. HbAlc & $0.814^{* *}$ & $\mathrm{I}$ & - \\
3. Anxiety & $0.654^{* *}$ & $0.528^{* *}$ & $\mathrm{I}$ \\
4. Depression & $0.796^{* *}$ & $0.675^{* *}$ & $0.683^{* *}$ \\
\hline
\end{tabular}

Note: $* * p<0.01$.

Abbreviation: $\mathrm{HbAlc}$, glycated haemoglobin.

there was a moderate positive significant correlation between alexithymia and anxiety $(P<0.01)$.

According to the multivariate analysis, alexithymia was 2.63 times more severe in participants working in a paid job (95\% confidence interval [CI]: 2.04-3.98), 2.09 times more severe in the participants whose $\mathrm{HbAlc}$ levels were $\geq 7.0 \%$ (95\% CI: 1.21-3.63), 3.77 times more severe in the participants whose anxiety subscale score was $\geq 11$ (95\% CI: 2.16-6.58), and 2.57 times more severe in the participants whose depression subscale score was $\geq 8(95 \%$ CI: 1.48-3.78) than in their counterparts (Table 5).

\section{Discussion}

Type $2 \mathrm{DM}$ is one of the most debated chronic diseases in recent years due to both the rapid increase in the number of cases with DM and the failure to achieve treatment goals. This present study intended to determine the prevalence of alexithymia in patients with type $2 \mathrm{DM}$ and the factors leading to alexithymia, and $\sim 40 \%$ of the participants were determined to be alexithymic. This prevalence is noteworthy and is of great importance not only because alexithymia affects the ability of people with DM to manage their disease but also because it prevents those people from receiving effective care and treatment. In studies conducted with patients having type $2 \mathrm{DM}, 75.8 \%$ of the participants in Hintistan et al' $\mathrm{s}^{24}$ study, $46.6 \%$ in Lemch et al' $\mathrm{s}^{25}$ study, and $65.0 \%$ in Topsever et al' $\mathrm{s}^{36}$ study were determined to have alexithymia. These results suggest that the prevalence of alexithymia in patients with type $2 \mathrm{DM}$ varies from one study to another, which may be due to the differences in study designs, measurement tools, and the participants' age and cultural traits.

In the literature, although some of the studies conducted with patients having DM have demonstrated a relationship between alexithymia and variables such as the female sex, ${ }^{36}$ lower educational level, ${ }^{24,36}$ low level of income, and longer duration of illness, ${ }^{24}$ some studies have reported that age, sex, level of education, duration of illness, type of treatment, and the presence of complications do not affect the severity of alexithymia. ${ }^{16,28}$ On the other hand, the results of this present study demonstrated that although some of the aforementioned
Table 5 Multivariate analysis of factors affecting alexithymia in patients with type 2 DM

\begin{tabular}{|c|c|c|c|c|}
\hline Variables $(n=326)$ & $\beta$ & SE & $P$-value & OR $(95 \% \mathrm{Cl})$ \\
\hline \multicolumn{5}{|l|}{ Age (years) } \\
\hline$\geq 65$ & & & & 1.00 \\
\hline $45-64$ & 0.204 & 0.331 & 0.538 & $1.23(0.64-2.34)$ \\
\hline \multicolumn{5}{|l|}{ Sex } \\
\hline Male & & & & 1.00 \\
\hline Female & 0.155 & 0.309 & 0.617 & $1.17(0.63-2.14)$ \\
\hline \multicolumn{5}{|l|}{ Education level } \\
\hline Secondary and high school & & & & 1.00 \\
\hline Primary school and lower & 0.321 & 0.241 & 0.118 & $2.11(0.7 I-3.43)$ \\
\hline \multicolumn{5}{|c|}{ Employment status } \\
\hline Does not work & & & & 1.00 \\
\hline Working & 1.221 & 0.376 & 0.001 & $2.63(2.04-3.98)$ \\
\hline \multicolumn{5}{|l|}{ Perceived income level } \\
\hline Good & & & & 1.00 \\
\hline Moderate & 0.044 & 0.718 & 0.951 & $1.04(0.26-4.27)$ \\
\hline Bad & 1.046 & 0.891 & $0.24 I$ & $2.84(0.49-6.32)$ \\
\hline \multicolumn{5}{|l|}{ Duration of illness (years) } \\
\hline$<1$ & & & & 1.00 \\
\hline $1-5$ & 0.660 & 0.392 & 0.092 & $0.52(0.24-1.11)$ \\
\hline $6-10$ & 0.542 & 0.380 & 0.154 & $1.71(0.82-3.62)$ \\
\hline$\geq 11$ & 0.373 & 0.379 & 0.324 & $1.45(0.69-3.05)$ \\
\hline \multicolumn{5}{|c|}{ Presence of a comorbid chronic disease } \\
\hline No & & & & 1.00 \\
\hline Yes & 0.346 & 0.313 & 0.269 & $0.7 \mid(0.38-|.3|)$ \\
\hline \multicolumn{5}{|l|}{ Type of treatment } \\
\hline Oral antidiabetic + diet & & & & 1.00 \\
\hline Insulin + diet & 0.455 & 0.281 & 0.141 & $1.74(0.84-3.01)$ \\
\hline \multicolumn{5}{|l|}{ Presence of complications } \\
\hline No & & & & 1.00 \\
\hline Yes & 0.243 & 0.312 & 0.436 & $1.28(0.69-2.35)$ \\
\hline \multicolumn{5}{|l|}{ HbA I c level (\%) } \\
\hline$<7$ & & & & 1.00 \\
\hline$\geq 7$ & $0.74 I$ & 0.280 & 0.008 & $2.09(1.21-3.63)$ \\
\hline \multicolumn{5}{|l|}{ Anxiety } \\
\hline$\leq 10$ & & & & 1.00 \\
\hline$\geq 11$ & 1.328 & 0.284 & 0.000 & $3.77(2.16-6.58)$ \\
\hline \multicolumn{5}{|l|}{ Depression } \\
\hline$\leq 7$ points & & & & 1.00 \\
\hline$\geq 8$ points & 0.454 & 0.291 & 0.019 & $2.57(1.48-3.78)$ \\
\hline
\end{tabular}

Notes: Hosmer-Lemeshow test: 0.784 , Nagelkerke $R^{2}: 0.241$.

Abbreviations: $\mathrm{Cl}$, confidence interval; DM, diabetes mellitus; HbAlc, glycated haemoglobin; OR, odds ratio; SE, standard error.

variables were associated with alexithymia, some of them were not. One of the variables associated with alexithymia was employment status. The participants who worked in a paid job were alexithymic, which can be explained by the fact that they had to deal with problems caused not only at work but also by the disease. In addition, the fact that almost half of these participants were at risk of anxiety and depression supports this finding. In order to clearly understand the variables affecting alexithymia in patients with $\mathrm{DM}$, there is a need for further studies on the issue. 
In the present study, another variable that affected alexithymia was the HbA1c levels. Alexithymic features were more common among those whose $\mathrm{HbA1c}$ level was $>7.0 \%$. This finding supports Abramson et al's ${ }^{16}$ view that alexithymia adversely affects glycemic control in patients with DM because it reduces their awareness of bodily sensations. Similarly, in several studies, poor glycemic control is stated to be associated with high levels of alexithymia. ${ }^{17,36}$ Another study conducted with patients with type 2 DM emphasized that alexithymia affected glycemic control more adversely than that affected by depression. ${ }^{26}$ Failure in achieving the target blood glucose levels in patients with DM has been indicated in many studies conducted both in Turkey and around the world. ${ }^{1-3,5}$ In the present study, glycemic control was not achieved in $\sim 64 \%$ of the patients. This finding is important because not only it shows that the glycemic control rate in patients with type 2 $\mathrm{DM}$ is not at a desirable level but it also reveals the relationship between alexithymia and various parameters of DM. Given the relationship between alexithymia and poor glycemic control, the importance of attempts to be made at the primary care facilities to achieve glycemic control becomes obvious.

In this present study, the patients at risk for anxiety were determined to be alexithymic about four times more than were the patients not at risk for anxiety. This finding indicates that the higher the severity of anxiety symptoms, the more difficulty the patients had in recognizing and describing their emotions. In the literature, it is stated that alexithymia functions as a coping mechanism to avoid intense sensation. ${ }^{37}$ The findings of the present study support the view that individuals with anxiety inhibit their emotional experiences and tend to display alexithymic behaviors because of fear of excessive stimulation of bodily sensations. In the study investigating the effects of alexithymic features on metabolic control in patients with type 1 DM, Luminet et $\mathrm{al}^{17}$ determined a relationship between anxiety and alexithymia; however, in the study investigating the role of obesity, depression, and anxiety in type $1 \mathrm{DM}$ patients with DM with poor glycemic control, Melin et $\mathrm{al}^{38}$ did not find any association between anxiety and alexithymia. There are few, if any, studies investigating the relationship between alexithymia and anxiety in people with DM. Therefore, various epidemiological studies may provide a better understanding of the causal relationship between anxiety and alexithymia.

Studies conducted with patients with DM have reported a positive significant correlation between alexithymia and depression..$^{27,28}$ In a study carried out with type 1 DM patients, alexithymia was reported to be a significant risk factor for depression in those people. ${ }^{38}$ Saarijärvi et al ${ }^{39}$ reported that depressive symptoms make it difficult for people to recognize their emotions and thus to share them with others. In the present study, the patients at risk of depression were found to show high alexithymic features. This finding is consistent with the findings of other studies in the literature.

\section{Limitations of the study}

Type $2 \mathrm{DM}$ is a disease the prevalence of which is rising rapidly. It leads to high mortality and morbidity, because despite developments in diagnosis and treatment, the desired goals have not yet been achieved in the treatment of DM. The findings of the present study are important because it addresses the results of poor glycemic control in type 2 DM from a different aspect. However, the study has some limitations. First, because it was conducted in a relatively small group of inpatients treated in a single secondary health facility, its results are applicable only to the patients surveyed, and thus they cannot be generalized to other patients. Another limitation of the study was that due to its cross-sectional nature, it only explains the correlational relationship between the variables affecting alexithymia and is not capable of showing the sequence. Longitudinal studies could provide more insight into the underlying mechanism of the relationships found in this study.

\section{Conclusion and recommendations}

Of the patients in the present study, $40 \%$ were alexithymic, $35 \%$ were at risk of anxiety, and $45 \%$ were at risk of depression. Poor glycemic control was determined to be a preventable risk factor for alexithymia, anxiety, and depression. These findings reveal the necessity of providing preventive mental health services in primary health care and consultation-liaison services in the secondary health care. Therefore, considering that alexithymia and psychological symptoms are a major factor in controlling DM, it is recommended that patients' treatments and follow-ups should be arranged to include mental health services, and intervention programs against alexithymia could be developed. It is also recommended to carry out field studies with larger samples in order to better explain the causal relationship between alexithymia and affecting factors in type $2 \mathrm{DM}$ patients, to control confounding variables, and to generalize the results to the community.

\section{Disclosure}

The authors report no conflicts of interest in this work.

\section{References}

1. American Diabetes Association (ADA). Standards of medical care in diabetes - 2015. Diabetes Care. 2015;38(1):1-93.

2. Satman I, Omer B, Tutuncu Y, et al. Twelve year trends in the prevalence and risk factors of diabetes and prediabetes in Turkish adults. Eur J Epidemiol. 2013;28(2):169-180. 
3. Wild S, Roglic G, Green A, et al. Global prevalence of diabetes: estimates for the year 2000 and projections for 2030. Diabetes Care. 2004; 27(5):1047-1053.

4. Jackson IL, Adibe MO, Okonta MJ, Ukwe CV. Medication adherence in type 2 diabetes patients in Nigeria. Diabetes Technol Ther. 2015;17(6):398-404

5. Turkey Public Health Institution (TPHI). Turkey Diabetes Program 2015-2020. Ankara: Kuban Publishing; 2014.

6. Ozdemir I, Hocaoglu C, Kocak M, Ersoz HO. Quality of life and psychiatric symptoms in the patients with type 2 diabetes mellitus. Dusunen Adam J Psychiatry Neurol Sci. 2011;24:128-138.

7. Young EE, Unachukwu CN. Psychosocial aspects of diabetes mellitus. Afr J Diabet Med. 2012;20(1):5-7.

8. Bahar A, Sertbas G, Sonmez A. Determination of depression and anxiety levels of patients with diabetes mellitus. Anatolian J Psychiatry. 2006; 7:18-26.

9. Collins M, Corcoran P, Perry I. Anxiety and depression symptoms in patients with diabetes. Diabet Med. 2009;26(2):153-161.

10. Lee HJ, Chapa D, Kao CW, et al. Depression, quality of life, and glycemic control in individuals with type 2 diabetes. J Am Acad Nurse Pract. 2009;21(4):214-224.

11. Lustman PJ, Clouse RE. Depression in diabetic patients: the relationship between mood and glycemic control. J Diabetes Complications. 2005; 19(2):113-122.

12. Papelbaum M, Lemos HM, Duchesne M, Kupfer R, Moreira RO, Coutinho WF. The association between quality of life, depressive symptoms and glycemic control in a group of type 2 diabetes patients. Diabetes Res Clin Pract. 2010;89(3):227-230.

13. Sulaiman N, Hamdan A, Tamim H, Mahmood DA, Young D. The prevalence and correlates of depression and anxiety in a sample of diabetic patients in Sharjah, United Arab Emirates. BMC Fam Pract. 2010;11(80):1-7.

14. Anderson RJ, Freedland KE, Clouse RE, Lustman PJ. The prevalence of comorbid depression in adults with diabetes: a meta-analysis. Diabetes Care. 2001;24(6):1069-1078.

15. Li C, Barker L, Ford ES, Zhang X, Strine TW, Mokdad AH. Diabetes and anxiety in US adults: findings from the 2006 Behavioral Risk Factor Surveillance System. Diabetic Med. 2008;25(7): 878-881.

16. Abramson L, McClelland DC, Brown D, Kelner S Jr. Alexithymic characteristics and metabolic control in diabetic and healthy adults. J Nerv Ment Dis. 1991;179(8):490-494.

17. Luminet O, de Timary P, Buysschaert M, Luts A. The role of alexithymia factors in glucose control of persons with type 1 diabetes: a pilot study. Diabetes Metab. 2006;32(5 Pt 1):417-424.

18. Sifneos PE. Alexithymia: past and present. Am J Psychiatry. 1996; 153(7 Suppl): 137-142.

19. Tordeurs D, Janne P. Alexithymie, santé et psychopathologie [Alexithymia, health and psychopathology]. Encephale. 2000;26:61-68. French.

20. Honkalampia K, Koivumaa-Honkanena H, Lehtoa SM, et al. Is alexithymia a risk factor for major depression, personality disorder, or alcohol use disorders? A prospective population-based study. JPsychosom Res. 2010; 68(3):269-273.

21. Lumley MA, Neely LC, Burger AJ. The assessment of alexithymia in medical settings: implications for understanding and treating health problems. J Pers Assess. 2007;89(3):230-246.
22. Mattila AK, Saarni SI, Salminen JK, Huhtala H, Sintonen H, Joukamaa M. Alexithymia and health-related quality of life in a general population. Psychosomatics. 2009;50(1):59-68.

23. Tolmunen T, Heliste M, Lehto SM, Hintikka J, Honkalampi K, Kauhanen J. Stability of alexithymia in the general population: an 11-year follow-up. Compr Psychiatry. 2011;52(5):536-541.

24. Hintistan S, Cilingir D, Birinci N. Alexithymia among elderly patients with diabetes. Pak J Med Sci. 2013;29(6):1344-1348.

25. Lemche AV, Chaban AS, Lemche E. Alexithymia as a risk factor for type 2 diabetes mellitus in the metabolic syndrome: a cross-sectional study. Psychiatry Res. 2014;215(2):438-443.

26. Luca A, Luca M, Di Mauro M, Palermo F, Rampulla F, Calandra C. Alexithymia, more than depression, influences glycaemic control of type 2 diabetic patients. J Endocrinol Invest. 2015;38(6):653-660.

27. Sapozhnikova IE, Tarlovskaia EI, Madianov IV, Vedenskaia TP. The degree of alexithymia in type 2 diabetes mellitus patients and its association with medical and demographic parameters. Ter Arkh. 2012;84(10): 23-27.

28. Friedman S, Vila G, Even C, et al. Alexithymia in insulin-dependent diabetes mellitus is related to depression and not to somatic variables or compliance. J Psychosoma Res. 2003;55(3):285-287.

29. Mnif L, Damak R, Mnif F, et al. Alexithymia impact on type 1 and type 2 diabetes: a case-control study. Ann Endocrinol. 2014;75(4):213-219.

30. Bagby RM, Taylor GJ, Parker JD. The twenty-item Toronto Alexithymia Scale-II. Convergent, discriminant, and concurrent validity. J Psychosom Res. 1994;38(1):33-40.

31. Sayar K, Gulec H, Ak I. Reliability and Validity Study of Toronto Alexithymia Scale. 37th National Psychiatry Symposium, Istanbul; October 2-6, 2001:130.

32. Gulec H, Kose S, Gulec MY, et al. Reliability and factorial validity of the Turkish version of the 20-item Toronto Alexithymia Scale (TAS-20). Bull Clin Psychopharmacol. 2009;19:214-220.

33. Zigmond AS, Snaith RP. The hospital anxiety and depression scale. Acta Psychiatrica Scandinavica. 1983;67(6):361-370.

34. Aydemir O, Guvenir T, Kuey L. Validity and reliability of Turkish version of Hospital Anxiety and Depression Scale. Turkish J Psychiatry. 1997;8:280-287.

35. World Health Organization (WHO). Use of Glycated Haemoglobin (HbAlc) in the Diagnosis of Diabetes Mellitus. Abbreviated Report of a WHO Consultation. Geneva: World Health Organization; 2011. Available from: http://www.who.int/diabetes/publications/reporthba1c_2011.pdf. Accessed January 24, 2016.

36. Topsever P, Filiz TM, Salman S, et al. Alexithymia in diabetes mellitus. Scott Med J. 2006;51(3):15-20.

37. Motan I, Gencoz T. The relationship between the dimensions of alexithymia and the intensity of depression and anxiety. Turkish J Psychiatry. 2007;18(4):333-343.

38. Melin EO, Thunander M, Svensson R, Landin-Olsson M, Thulesius HO Depression, obesity, and smoking were independently associated with inadequate glycemic control in patients with type 1 diabetes. Eur J Endocrinol. 2013;168(6):861-869.

39. Saarijärvi S, Salminen JK, Toikka TB. Alexithymia and depression: a 1-year follow-up study in outpatients with major depression. J Psychosom Res. 2001;51(6):729-733.

\section{Dovepress}

\section{Publish your work in this journal}

Patient Preference and Adherence is an international, peer-reviewed, open access journal that focuses on the growing importance of patient preference and adherence throughout the therapeutic continuum. Patient satisfaction, acceptability, quality of life, compliance, persistence and their role in developing new therapeutic modalities and compounds to optimize

clinical outcomes for existing disease states are major areas of interest for the journal. This journal has been accepted for indexing on PubMed Central. The manuscript management system is completely online and includes a very quick and fair peer-review system, which is all easy to use. Visit http://www. dovepress.com/testimonials.php to read real quotes from published authors. 